\title{
Efficacy and safety of food fortification with calcium among adults in Finland
}

\author{
Tero Hirvonen ${ }^{1}$ * , Heli Tapanainen ${ }^{1}$, Liisa Valsta ${ }^{1}$, Marja-Leena Hannila ${ }^{1}$, Antti Aro ${ }^{2}$ \\ and Pirjo Pietinen ${ }^{1}$ \\ ${ }^{1}$ National Public Health Institute, Department of Epidemiology and Health Promotion, Mannerheimintie 166, \\ FIN-00300 Helsinki, Finland: ${ }^{2}$ National Public Health Institute, Department of Health and Functional Capacity, \\ Helsinki, Finland
}

Submitted 27 June 2005: Accepted 26 October 2005

\begin{abstract}
Objective: To examine the efficacy and safety of foods fortified with calcium in the adult population in Finland.

Design: A simulation study based on the FINDIET 2002 Survey, which estimated habitual food consumption, dietary supplement use and nutrient intakes using 48hour recall and two 3-day food records, and an Internet survey of the consumption of fortified foods and dietary supplements.

Setting/participants: Participants of FINDIET 2002 were 25-64 years old from five areas $(n=2007)$. Participants of the Internet-based survey $(n=1537)$ were over 15 years of age from all over the country.

Results: If all potentially fortifiable foods were to be fortified with calcium, the proportion of participants with calcium intake below the recommended level $\left(<800 \mathrm{mg} \mathrm{day}^{-1}\right)$ would decrease from $20.3 \%$ to $3.0 \%$ in men and from $27.8 \%$ to $5.6 \%$ in women compared with the situation where no foods were fortified. At the same time, the proportion of participants with calcium intake above the tolerable upper intake level (UL, $>2500 \mathrm{mg} \mathrm{day}^{-1}$ ) would increase from $0.6 \%$ to $12.7 \%$ in men and from $0.1 \%$ to $3.8 \%$ in women. However, in a probability-based model (11\% of all fortifiable foods to be fortified with calcium) the proportion of participants with calcium intake below the recommended level would be $15.7 \%$ in men and $23.2 \%$ in women. The proportion with intake above the UL in this model would be $1.2 \%$ in men and $0.7 \%$ in women. Conclusions: Food fortification would be a relatively effective and safe way to increase the calcium intake of the Finnish adult population.
\end{abstract}

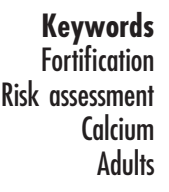

Adequate calcium intake is essential for obtaining sufficient peak bone mass in youth and thus for minimising bone loss later in life $^{1}$. In addition, high calcium intake has been observed to be associated with a low risk of colorectal cancer ${ }^{2,3}$ and possibly also with low blood pressure ${ }^{4,5}$. However, a high intake of calcium may inhibit the absorption of iron, phosphorus, magnesium and zinc $^{6}$. Furthermore, there is some evidence that a very high ( $>2000 \mathrm{mg} \mathrm{day}^{-1}$ ) intake of calcium may be associated with an elevated risk of prostate cancer ${ }^{7}$.

In Finland, calcium intake is sufficient on average among the adult population ${ }^{8}$. However, the prevalence of lactose intolerance is about $17 \%{ }^{9}$. Even though a wide variety of low-lactose dairy products is available, lactose-intolerant individuals have a lower calcium intake than other people, particularly among women ${ }^{10}$. Therefore, there is a need to increase calcium intake in some population groups. Since 2002, Finnish legislation has permitted the fortification of fruit juices with calcium at $120 \mathrm{mg} / 100 \mathrm{ml}$. Fortification of other food products with calcium still requires special permission from the National Food Agency. In recent years many food products fortified with calcium (especially fruit juices) have appeared on the market. However, the range of adequate and safe intake of calcium is quite narrow (800$2500 \mathrm{mg} \mathrm{day}^{-1}$ ) even for adults ${ }^{11,12}$. Therefore, food fortification with calcium poses a risk that, in some population groups, calcium intake could exceed the tolerable upper intake level. Furthermore, it is not known whether food fortification would actually decrease the proportion of individuals with low calcium intake. Thus, the aim of the present study was to determine whether food fortification with calcium could be considered safe and whether it could decrease the proportion of the adult Finnish population with low intake.

\section{Subjects and methods}

Data on calcium intake from natural sources and from food supplements was obtained from the FINDIET 2002 Survey, carried out as part of the FINRISK 2002 Study 
which monitors cardiovascular risk factors ${ }^{8}$. A random sample of 12000 persons aged 25-64 years in six areas, stratified by sex, area and 10-year age groups, was taken from the population register. The participation rate was $65 \%$, i.e. 7784 subjects.

The study FINDIET was carried out in five areas: (1) Helsinki area; (2) the cities of Turku and Loimaa and some rural communities in south-western Finland; and in the provinces of (3) North Carelia, (4) North Savo and (5) Oulu. Of the invited subjects 32\% were randomly selected also to the dietary survey. The final sample for the dietary survey was 2007 subjects. The participants were interviewed using the 48-hour recall. The dietary intake data consisted of all days of the week except Fridays. A subsample $(n=247)$ of the participants filled in a 3-day food record twice (the first starting the day after the 48-hour recall in early spring and the second in autumn). This survey did not provide information on the use of fortified foods in a systematic way. The National Food Composition Database FINELI ${ }^{\circledR}$ (www.fineli.fi) was used to calculate the intake of calcium from foods.

The use of dietary supplements during the previous 6 months was collected in a questionnaire. Participants filled in the brand name of the supplement, dosage and frequency of use. A separate dietary supplement database was used to calculate the intake of calcium from supplements.

Data on the consumption of fortified foods and food supplements were obtained from an Internet-based survey conducted by the Finnish Gallup for the National Food Agency $^{13}$. The survey consisted of 1537 men and women over 15 years of age. The participation rate was $72 \%$. The participants were asked following question: 'Which of the following fortified foods ( $=$ food with added vitamins or minerals) do you use (a) regularly, (b) occasionally ( = you have used it during the past 6 months): Fruit juices fortified with vitamin $\mathrm{C}$, fruit juices fortified with calcium, fruit juices fortified with several vitamins, ready-to-eat breakfast cereals fortified with vitamins and/or minerals, dairy products fortified with calcium, yoghurts fortified with several vitamins, soy products fortified with calcium, sweets fortified with vitamins and/or minerals'. For those who indicated having used some of these products the brand name was asked. There were similar questions concerning the use of dietary supplements.

The proportion of consumption of foods fortified with calcium was estimated for all potentially fortifiable foods from both the Internet-based survey and the FINDIET 2002 Survey. In the Internet-based survey, the proportion of individuals who used fruit juices fortified with calcium was $6 \%$ of men and $7 \%$ of women. Since $54 \%$ of men and $61 \%$ of women were users of fruit juice according to FINDIET 2002, we estimated that fruit juice fortified with calcium would be consumed by $11.1 \%$ of men and $11.5 \%$ of women. These proportions (11.1\%/11.5\%) were also used as a proxy for other potentially fortifiable foods, since there was no information on the consumption of other foods fortified with calcium.

The modelling of calcium intake was conducted with two methods: what-if models and probabilistic modelling. A flow-chart of the data is shown in Fig. 1. In the what-if models it was assumed that all products of the food group (e.g. fruit juices) would be fortified with calcium. The models were constructed simulating their appearance on the market, i.e. adding them to the model one by one in the following order (calcium content after fortification in parentheses): (1) fruit juices $(90 \mathrm{mg} /$ $100 \mathrm{ml}$ ); (2) milk and sour milk (180 mg/100 ml); (3) spreads $(620 \mathrm{mg} / 100 \mathrm{ml})$; (4) yoghurt and milk-based desserts (640 mg/100 g); (5) bread (145 mg/100 g). The calcium intake from foods and dietary supplements was estimated using the method of Nusser et al. ${ }^{14}$. This method gives the long-run average of daily intakes (usual daily intake) by taking into account day-to-day correlation and nuisance effects (such as day of the week and interview sequence). It also allows exceptions from normality

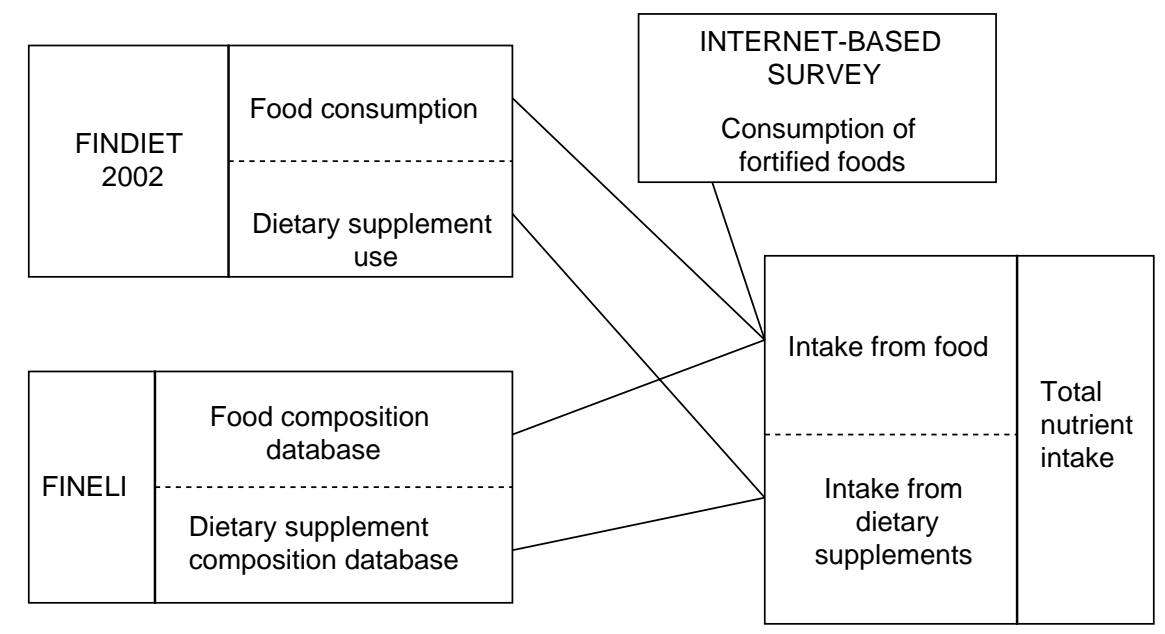

Fig. 1 Flow-chart of data used in the modelling. Data obtained from the Internet-based survey were used in simulations only 
through grafted polynomial transformations and recognises the measurement error associated with one-day dietary intakes. The estimations were done using the SASbased SIDE ${ }^{\circledR}$ program (SAS Institute, Cary, NC, USA).

In the probabilistic models the simulation method of Iman and Conover ${ }^{15}$ was used, since the models included data from different sources (FINDIET 2002 and Internetbased survey) that could not be merged. The models took into account the consumption of potentially fortifiable foods and the distributions of users of fortified foods and dietary supplements.

The correlations between the use of fortifiable foods (fruit juices, milk and sour milk, spreads, yoghurt and milk-based desserts, and bread) and the use of dietary supplements (estimated from FINDIET 2002), and between the use of dietary supplements and the use of fortified foods (estimated from the Internet survey), were also used in these models. The proportion of users of fortifiable foods was estimated among the sub-sample participants of FINDIET 2002 whose two 3-day food records were available in addition to the 48-hour recall $(n=247)$. The proportion of users of fortified foods was estimated using the Internet-based survey. Simulations were made using the @ Risk program (Palisade Corporation, Ithaca, NY, USA). Empirical cumulative distributions were used in the models.

Cut-off values for calcium intake were the recommended daily intake for adults $\left(800 \mathrm{mg} \mathrm{day}^{-1}\right)$ defined by the Nordic Council of Ministers ${ }^{11}$ and the tolerable upper intake level (UL, $2500 \mathrm{mg} \mathrm{day}^{-1}$ ) defined by the Scientific Committee of Food of the European Commis$\operatorname{sion}^{12}$.

\section{Results}

Characteristics of the subjects are presented in Table 1. The main sources of calcium were milk and sour milk $(33.2 \%, 27.8 \%)$, cheese $(24.2 \%, 23.6 \%)$ and yoghurt (4.1\%, $6.9 \%)$ in men and women, respectively.

If all milk and sour milk, bread, yoghurt and milk-based desserts, fruit juice and spreads were to be fortified with calcium (what-if models), calcium intake would increase markedly compared with the situation where no foods were fortified (Fig. 2). Of all the fortifiable foods studied, fortified bread, milk and sour milk, and spreads had the highest impact on both the mean calcium intake and the proportion of individuals whose calcium intake was below the recommended intake or above the UL (Table 2).

In the probability-based models, the increases in calcium intake by fortification were smaller than those obtained with what-if models (Fig. 3). In men, the proportion with calcium intake below the recommended daily level would be reduced to almost half in the model where the proportion of calcium fortification was 25\% compared with the model with no fortification, and further to almost a quarter in the model where calcium

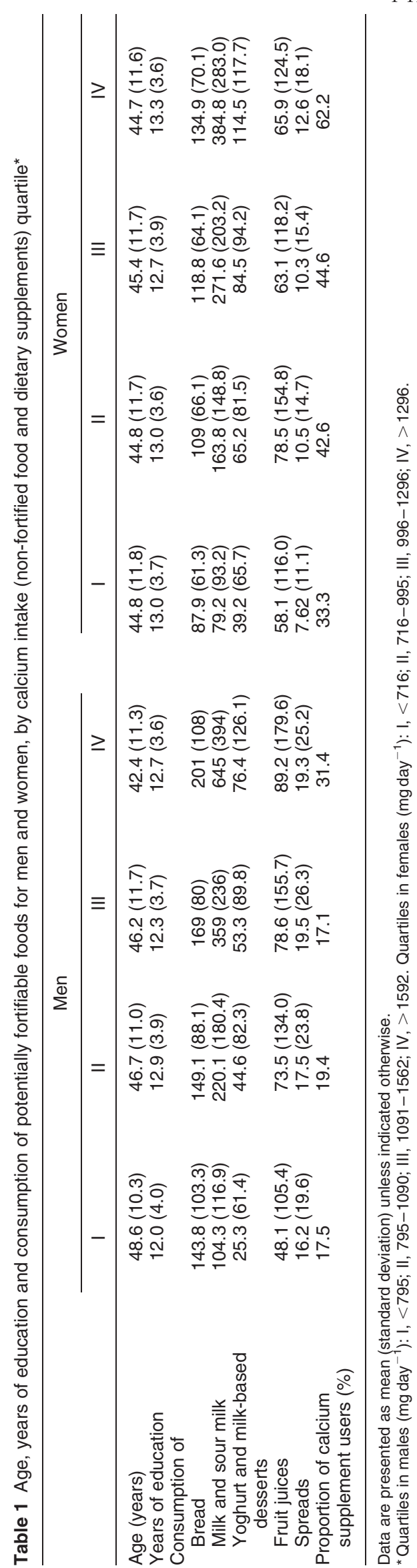



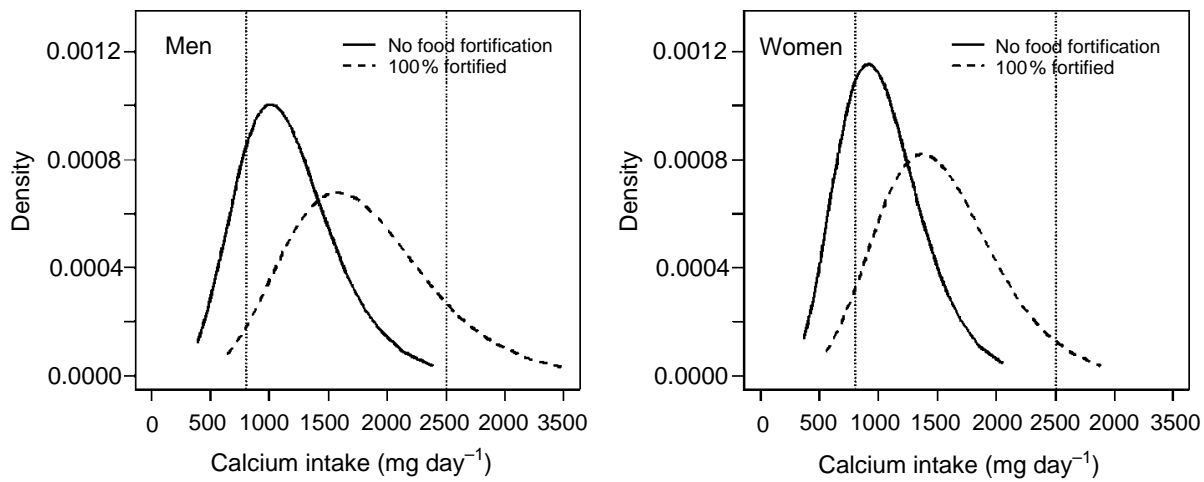

Fig. 2 Estimated density function for usual calcium intake without and with fortification in the what-if models. Calcium intake was adjusted by age, region and day of the week

fortification proportion was 50\% (Table 3). On the other hand, the proportion of individuals with calcium intake above the UL increased with increasing extent of calcium fortification.

\section{Discussion}

Our results indicate that food fortification is quite safe and relatively effective in decreasing the proportion of adults with calcium intake below the recommended level. However, if calcium fortification proportion was 50\%, in men at least the proportion exceeding the UL became significant.

Generally, our study is in line with others conducted previously $^{16-19}$. However, the comparison with previous studies is somewhat difficult, since in only one of them ${ }^{19}$ was calcium from dietary supplements taken into account. In a Danish study, flour fortification with calcium was found to decrease the proportion of adults with low calcium intake from $22 \%$ to $6 \%{ }^{16}$. In a previous Finnish study, it was observed that fortification could result in excessive calcium intake in the highest decile ${ }^{17}$. In an Irish study ready-to-eat breakfast cereals had a minor impact on calcium intake, even though the contribution of breakfast cereals was significant for several other nutrients ${ }^{18}$. A Canadian study tried to define a fortification scenario that would reduce the proportion of the population with low intakes while minimising the proportion that could exceed the $\mathrm{UL}^{19}$. However, this goal proved difficult to achieve, since any scenario that increased the mean calcium intake in women to near the adequate level led to $6-7 \%$ of the men exceeding the UL.

Our study has several strengths. First, we were able to take account of calcium intake from dietary supplements. Second, data on the use of fortified foods were available and could be used in probabilistic modelling. With this method the intake estimates obtained are more realistic than in the case where one relies on calculations in which it is assumed that all fortifiable foods are actually fortified.

A clear weakness of our study is the high proportion of energy underreporting in dietary surveys, also found in the FINDIET survey ${ }^{20}$. Therefore, it is possible that calcium intake is also affected by underreporting and that the proportion of individuals with calcium intake above the UL would be underestimated. In addition, our information concerning the use of fortified products is rather limited. Data used in our study were obtained from an Internetbased survey which did not inquire about the consumption of all fortified foods that were available. In addition, some of the fortifiable foods were not available at the time of the survey (bread, spreads). Furthermore, it was obvious that at least some of the participants did not know

Table 2 Impact of fortification of individual foods or food groups on daily calcium intake in a model that assumes all fortifiable foods to be fortified with calcium

\begin{tabular}{|c|c|c|c|c|c|c|}
\hline & \multicolumn{2}{|c|}{$\begin{array}{l}\text { Calcium intake } \\
\left(\mathrm{mg} \mathrm{day}^{-1}\right)\end{array}$} & \multicolumn{2}{|c|}{$\begin{array}{c}\text { Intake } \\
<800 \mathrm{mg} \mathrm{day}^{-1} \\
(\%)\end{array}$} & \multicolumn{2}{|c|}{$\begin{array}{c}\text { Intake } \\
>2500 \mathrm{mg} \mathrm{day}^{-1} \\
(\%)\end{array}$} \\
\hline & Men & Women & Men & Women & Men & Women \\
\hline From natural sources and dietary supplements & $1159(426)$ & $1036(363)$ & 20.3 & 27.8 & 0.64 & 0.10 \\
\hline +Fruit juices $(10+80 \mathrm{mg} / 100 \mathrm{ml})^{*}$ & $1230(456)$ & $1109(376)$ & 17.0 & 21.1 & 1.1 & 0.2 \\
\hline+ Milk and sour milk $(121+51 \mathrm{mg} / 100 \mathrm{ml})^{*}$ & $1422(569)$ & $1243(446)$ & 12.3 & 15.5 & 4.5 & 0.93 \\
\hline + Spreads $(28+592 \mathrm{mg} / 100 \mathrm{~g})^{*}$ & $1528(584)$ & $1303(461)$ & 8.4 & 12.7 & 6.3 & 1.4 \\
\hline + Yoghurt and milk-based desserts $(108+531 \mathrm{mg} / 100 \mathrm{~g})$ & $1572(595)$ & $1370(477)$ & 7.4 & 10.2 & 7.3 & 2.0 \\
\hline+ Bread $(16+129 \mathrm{mg} / 100 \mathrm{~g})^{*}$ & $1784(619)$ & $1519(503)$ & 3.0 & 5.6 & 12.7 & 3.8 \\
\hline
\end{tabular}

Data are presented as mean (standard deviation) or \%.

*Average calcium content expressed as natural calcium + fortified calcium. 

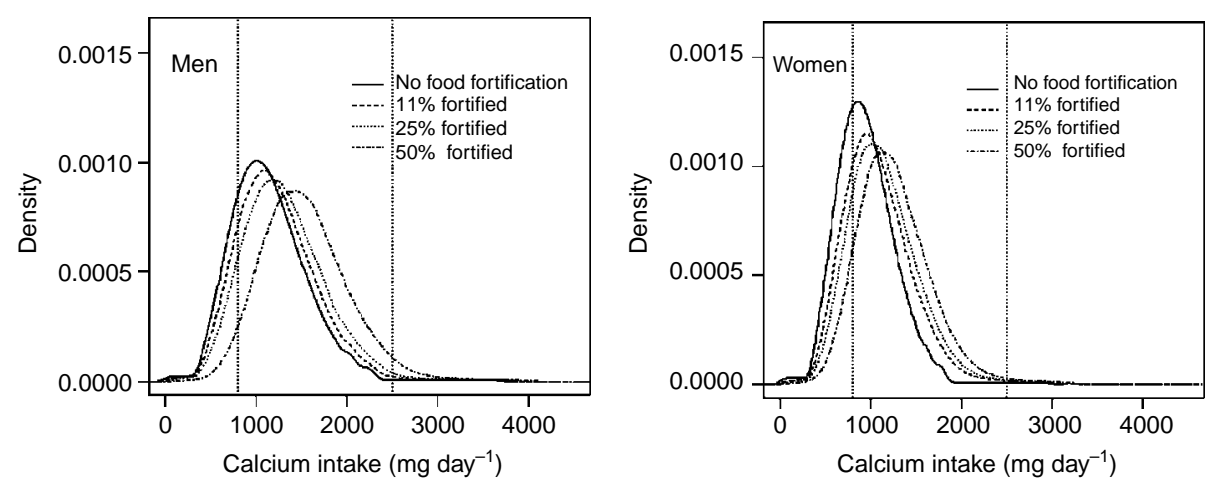

Fig. 3 Estimated density function for calcium intake in probabilistic models without fortification and with different proportions of food fortified with calcium

if the consumed product was fortified or not, since when they were asked to name the fortified products they consumed it was noted that many of these products were actually not fortified.

The risk and benefit of foods fortified with calcium differed substantially between genders. The higher calcium intake of men in all models is due to their higher total food consumption. In addition, consumption of potentially fortifiable foods is higher in men than in women. Therefore, it is difficult to fortify foods so that the proportion of women with intake below the recommended level would decrease markedly without increasing significantly the proportion of men exceeding the UL. This was also seen in the Canadian study ${ }^{19}$. One solution could be that foods which are consumed more by women than by men (e.g. yoghurt and mineral water) should be fortified with calcium.

It is surprising that even though calcium intake on average is quite high, food fortification did not lead to any major increase in the proportion of the population exceeding the UL, especially in the model which was closest to the prevailing situation (11\% of potentially fortifiable foods being fortified). However, there is a risk that a significant proportion of the population would exceed the UL if the calcium fortification proportion increases, especially if this food is eaten in large amounts (e.g. bread) or by a large proportion of population (e.g. milk). This could increase the risk of harmful effects of high calcium intake, i.e. deterioration of zinc, magnesium or iron status or hypercalcaemia, in some population groups.

Food fortification with calcium has also benefits since it could reduce markedly the proportion of individuals with very low intakes; in particular, those individuals who do not consume dairy products could benefit from products fortified with calcium. The problem is how to target the fortified foods to these consumers. Proper food labelling could be one strategy. This could also diminish the risk that fortified foods are consumed unintentionally. Another strategy could be consumer guidance and marketing. Overall, we estimate that food fortification with calcium would confer more benefits than risks, since fortification decreased the proportion of individuals with low calcium intake much more than it increased the proportion of individuals with intake above the UL.

An alternative to food fortification could be dietary supplements. They have the benefit of standard dosage with no risk of overdose if dosage instructions are followed.

Table 3 Effect of different calcium fortification proportions on the distribution of calcium intake in probabilistic models

\begin{tabular}{|c|c|c|c|c|c|c|c|}
\hline & \multicolumn{5}{|c|}{ Calcium intake $\left(\mathrm{mg} \mathrm{day}^{-1}\right)$} & \multirow[b]{2}{*}{$\begin{array}{c}\text { Intake } \\
<800 \text { mg day }^{-1}(\%)\end{array}$} & \multirow[b]{2}{*}{$\begin{array}{c}\text { Intake } \\
>2500 \mathrm{mg} / \mathrm{day}^{-1}(\%)\end{array}$} \\
\hline & Mean & $\mathrm{P}_{25}$ & $\mathrm{P}_{50}$ (median) & $\mathrm{P}_{75}$ & $P_{95}$ & & \\
\hline \multicolumn{8}{|l|}{ Men } \\
\hline No fortification & 1164 & 857 & 1110 & 1410 & 1931 & 20.0 & 0.97 \\
\hline $11 \%$ of products fortified ${ }^{*}$ & 1232 & 914 & 1180 & 1488 & 2028 & 15.7 & 1.2 \\
\hline $25 \%$ of consumed food fortified ${ }^{*}$ & 1318 & 992 & 1268 & 1586 & 2134 & 11.4 & 1.6 \\
\hline $50 \%$ of consumed food fortified ${ }^{*}$ & 1473 & 1135 & 1426 & 1753 & 2315 & 5.8 & 2.8 \\
\hline \multicolumn{8}{|l|}{ Women } \\
\hline No fortification & 1036 & 774 & 989 & 1243 & 1697 & 28.0 & 0.57 \\
\hline $11 \%$ of consumed food fortified ${ }^{*}$ & 1086 & 818 & 1038 & 1301 & 1762 & 23.2 & 0.7 \\
\hline $25 \%$ of consumed food fortified ${ }^{*}$ & 1150 & 875 & 1104 & 1371 & 1842 & 17.7 & 0.8 \\
\hline $50 \%$ of consumed food fortified ${ }^{*}$ & 1265 & 982 & 1219 & 1495 & 1978 & 10.4 & 1.2 \\
\hline
\end{tabular}

$\mathrm{P}$ - percentile.

*Total average calcium content: fruit juices, $90 \mathrm{mg} / 100 \mathrm{ml}$; milk and sour milk, $180 \mathrm{mg} / 100 \mathrm{ml}$; spreads, $620 \mathrm{mg} / 100 \mathrm{~g}$; yoghurt and milk-based desserts, $639 \mathrm{mg} / 100 \mathrm{~g}$; bread, $145 \mathrm{mg} / 100 \mathrm{~g}$. 
The drawbacks of dietary supplements are their high cost and low compliance. In addition, if supplements are taken in addition to fortified foods, the risk of exceeding the UL is pronounced - especially in Nordic countries where the consumption of dietary supplements is high ${ }^{21}$. In the present study, $11 \%$ of the respondents reported using both calcium-fortified foods and dietary supplements. Therefore, we do not recommend dietary supplements as an alternative to food fortification. However, if calcium intake from natural sources and fortified foods is low, dietary supplement use is warranted. The importance of consumer guidance and the labelling of fortified foods and dietary supplements must be highlighted.

We conclude that food fortification with calcium is safe provided that less than half of the potentially fortifiable food is fortified. Calcium fortification could be a good tool to increase safely the calcium intake among individuals with very low calcium intake provided that these foods are targeted correctly by labelling and marketing.

\section{Acknowledgements}

MSc Maija Heikkilä is acknowledged for updating the dietary supplement database and entering the supplement consumption data.

\section{References}

1 Flynn A. The role of dietary calcium in bone health. Proceedings of the Nutrition Society 2003; 62: 851-8.

2 Cho E, Smith-Warner SA, Spiegelman D, Beeson WL, van den Brandt PA, Colditz GA, et al. Dairy foods, calcium, and colorectal cancer: a pooled analysis of 10 cohort studies. Journal of the National Cancer Institute 2004; 96: 1015-22.

3 Flood A, Peters U, Chatterjee N, Lacey JV Jr, Schairer C, Schatzkin A. Calcium from diet and supplements is associated with reduced risk of colorectal cancer in a prospective cohort of women. Cancer Epidemiology, Biomarkers \& Prevention 2005; 14: 126-32.

4 Allender PS, Cutler JA, Follmann D, Cappuccio FP, Pryer J, Elliott P. Dietary calcium and blood pressure: a meta-analysis of randomized clinical trials. Annals of Internal Medicine 1996; 124: 825-31.

5 Cappuccio FP, Elliott P, Allender PS, Pryer J, Follman DA, Cutler JA. Epidemiologic association between dietary calcium intake and blood pressure: a meta-analysis of published data. American Journal of Epidemiology 1995; 142: 935-45.

6 Whiting SJ, Wood RJ. Adverse effects of high-calcium diets in humans. Nutrition Reviews 1997; 55: 1-9.
7 Dagnelie PC, Schuurman AG, Goldbohm RA, Van den Brandt PA. Diet, anthropometric measures and prostate cancer risk: a review of prospective cohort and intervention studies. BJU International 2004; 93: 1139-50.

8 Männistö S, Ovaskainen M-L, Valsta L, eds. The National FINDIET 2002 Study. Publication B3/2003. Helsinki: National Public Health Institute, 2003.

9 Sahi T, Launiala K, Laitinen H. Hypolactasia in a fixed cohort of young Finnish adults - a follow-up study. Scandinavian Journal of Gastroenterology 1983; 18: 865-70.

10 Honkanen R, Kroger H, Alhava E, Turpeinen P, Tuppurainen M, Saarikoski S. Lactose intolerance associated with fractures of weight-bearing bones in Finnish women aged 38-57 years. Bone 1997; 21: 473-7.

11 Nordic Council of Ministers. Nordic Nutrition Recommendations 2004 - Integrating Nutrition and Physical Activity. Nord 2004;13. Copenhagen: Nordic Council of Ministers, 2004 .

12 Scientific Committee on Food, European Commission (EC). Opinion of the Scientific Committee on Food on the Tolerable Upper Intake Level of Calcium. Brussels: Scientific Committee on Food, EC, 2003.

13 Raulio S. Ravitsemuksellisesti täydennettyjen elintarvikkeiden käyttö ja sen taustatejijät suomalaisilla aikuisilla. Suomen Lääkarilebti. Finlands Läkartidning 2003; 58: 1685-8.

14 Nusser SM, Carriquiry KW, Dodd KW, Fuller WA. A semiparametric transformation approach to estimating usual daily intake distribution. Journal of the American Statistical Association 1996; 91: 1440-9.

15 Iman RL, Conover WJ. A distribution-free approach to including rank correlation among input variables. Communications in Statistics: Simulations and Computations 1982; 11: 311-34.

16 Osler M, Heitmann BL. Food patterns, flour fortification, and intakes of calcium and vitamin D - a longitudinal study of Danish adults. Journal of Epidemiology and Community Health 1998; 52: 161-5.

17 Suojanen A, Raulio S, Ovaskainen M-L. Liberal fortification of foods: the risks - a study relating to Finland. Journal of Epidemiology and Community Health 2002; 56: 259-64.

18 Galvin MA, Kiely M, Flynn A. Impact of ready-to-eat breakfast cereal (RTEBC) consumption on adequacy of micronutrient intakes and compliance with dietary recommendations in Irish adults. Public Health Nutrition 2003; 6: $351-63$.

19 Johnson-Down L, L'Abbé MR, Lee NS, Gray-Donald K. Appropriate calcium fortification of the food supply presents a challenge. Journal of Nutrition 2003; 133: 2232-8.

20 Hirvonen T, Männistö S, Roos E, Pietinen P. Increasing prevalence of underreporting does not necessarily distort dietary surveys. European Journal of Clinical Nutrition 1997; 51: 297-301.

21 Peetz-Schou M. Nordic legislative practises and consumer attitudes towards the addition of nutrients to foods. Scandinavian Journal of Nutrition 1999; 43: 125S-8S. 